\title{
Sister chromatid fusion initiates amplification of the dihydrofolate reductase gene in Chinese hamster cells
}

\author{
Chi $\mathrm{Ma}_{r}{ }^{1-3}$ Stuart Martin, ${ }^{1}$ Barbara Trask, ${ }^{4,5}$ and Joyce L. Hamlin ${ }^{1,2,6}$ \\ ${ }^{1}$ Department of Biochemistry and ${ }^{2}$ Cell and Molecular Biology Program, University of Virginia School of Medicine, \\ Charlottesville, Virginia 22908 USA; ${ }^{4}$ Biomedical Sciences Division, Lawrence Livermore National Laboratory, \\ Livermore, California 94550 USA
}

\begin{abstract}
We have utilized a dihydrofolate reductase (DHFR) probe in combination with selected probes from other positions along the $2 q$ chromosome arm in a two-color fluorescence in situ hybridization analysis of early DHFR gene amplification events in CHO cells. These studies show clearly that the most frequent initiating event is the formation of a giant inverted duplication, resulting either from chromosome breakage and terminal fusion or a reverse unequal sister chromatid exchange. The dicentric chromosomes thus formed initiate bridge/breakage/fusion cycles that appear to mediate subsequent amplification steps to higher copy number.
\end{abstract}

[Key Words: DHFR gene; gene amplification; CHO cells; sister chromatid fusion; bridge/breakage/fusion]

Received December 15, 1992; revised version accepted January 29, 1993.

The amplification of specific genes can mediate the acquisition of drug resistance in mammalian cell lines and in some human tumors (Horns et al. 1984; Trent et al. 1984; Bishop 1987; Hamlin et al. 1991; Schimke 1988; Stark et al. 1989|. In addition, the amplification of oncogenes occurs at a very high frequency in human malignancies and is usually correlated with the more progressive stages of the particular disease (Bishop 1987; Hamlin et al. 1991). With very rare exceptions (see Prody et al. 1989), DNA sequence amplification has not been observed in normal, non-neoplastic cells (Sager et al. 1985; Otto et al. 1989; Tlsty 1990; Wright et al. 1990).

The number of amplicons per cell can vary from a few to $>10,000$ (Stark and Wahl 1984; Hamlin et al. 1991). Virtually all of the examples of mammalian DNA sequence amplification studied in detail thus far share certain properties: $(1)$ in the initial stages, megabase-long segments of DNA containing the selectable gene are amplified (Zieg et al. 1983; Trask and Hamlin 1989; Smith et al. 1990; Toledo et al. 1992); (2) both within and among cell lines there is heterogeneity in the size of the repeating units, but in a given drug-resistant clone, one or a few smaller amplicon types usually become dominant as the amplicon number increases during further selections (Ardeshir et al. 1983; Federspiel et al. 1984;

\footnotetext{
${ }^{3}$ Present addresses: Metabolism Branch, National Cancer Institute, Bethesda, Maryland 20892 USA; ${ }^{5}$ Department of Molecular Biotechnology, University of Washington, Seattle, Washington 98195 USA.

${ }^{6}$ Corresponding author.
}

Debatisse et al. 1986; Ma et al. 1988); (3) the multiple amplicons are arrayed in tandem, either in the body of chromosomes as abnormally banding regions (ABRs; Biedler and Spengler 1975) or as acentromeric, autonomously replicating episomal elements (termed double minutes; Kaufman et al. 1979; Barker 1982).

Although some information is available concerning the structure and disposition of amplicons late in the amplification process (see Ardeshir et al. 1983; Federspiel et al. 1984; Debatisse et al. 1986; Guilotto et al. 1986; Looney and Hamlin 1987; Looney et al. 1988; Ma et al. 1988), very little is known about the molecular mechanisms that initiate and perpetuate the amplification process in any mammalian system. The following models have been proposed (for review, see Schimke 1982, Stark and Wahl 1984; Hamlin et al. 1991): (1) unequal sister chromatid exchange (USCE) could result in the juxtaposition of both copies of a locus on one chromosome arm, presumably followed by additional rounds of USCE (Fig. 1A); (2) multiple rounds of replication could occur at a locus in a single cell cycle, followed by recombination of the extra duplexes in tandem arrays, either in loco or elsewhere in the genome (Fig. 1B); (3) the locus could be deleted from the chromosome, followed by amplification during its lifetime as an episome by unequal segregation or other means (Fig. 1C; Wahl 1989); or (4) a single- or double-strand break could initiate rollin replication analogous to conservative transposition in bacteriophage $\mathrm{Mu}$ (Galas and Chandler 1981; Harshey and Bukhari 1981; Fig. 1D). Amplification could be ini- 
Figure 1. Models for initial amplification events in CHO cells. (A) Two different unequal sister chromatid exchange events are pictured that would lead to an initial duplication of the DHFR gene. (B) An overreplication model is pictured that would lead to amplification either in loco if the extra duplexes were integrated close to the original locus or at a distant position if the extra duplexes had a finite extrachromosomal existence. The length of the amplicons may be shortened during the process. (C) A deletion model in which the deleted locus forms an episome that increases in size and gene copy number, possibly by rolling circle replication or unequal segregation and recombination; the episome then either remains extrachromosomal or reintegrates into the same or another chromosome, possibly after having been trimmed. $(D)$ A conservative transposition model in which extra copies of the locus in question are generated by a roll-in replication mechanism analogous to transposition in bacteria, but the original locus remains intact (Harshey and Bukhari 1980; Galas and Chandler 1981).
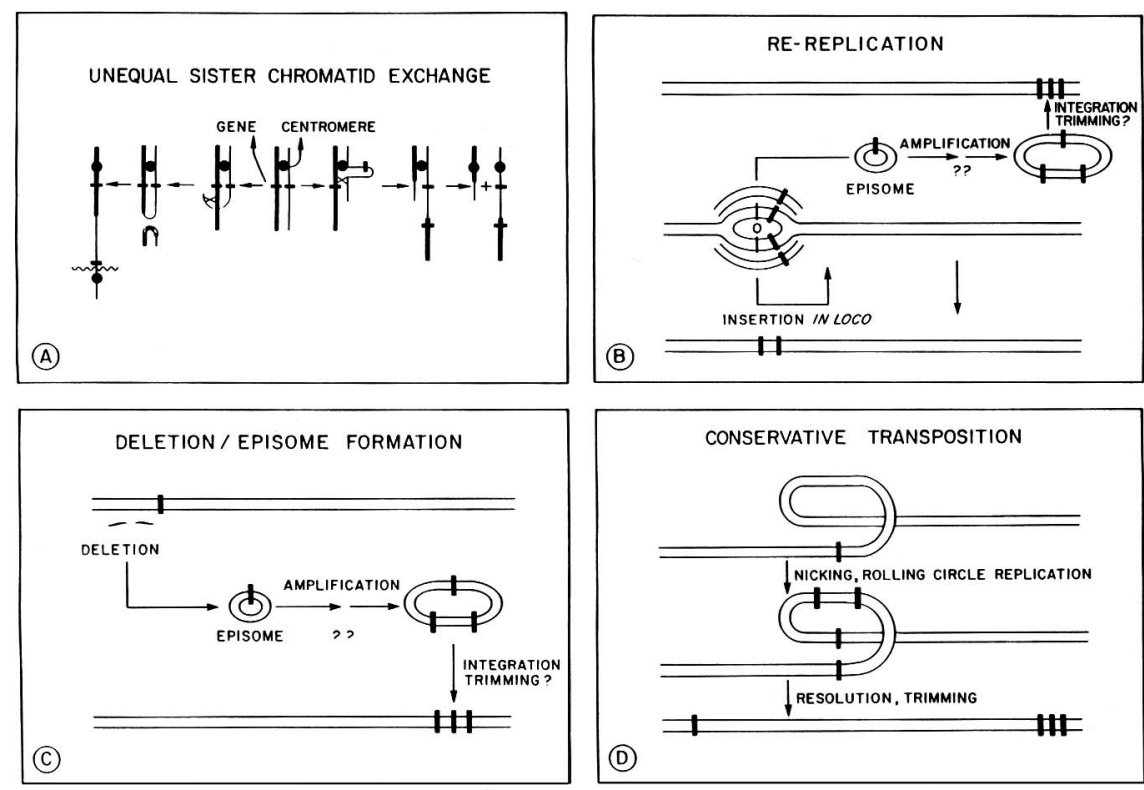

tiated by more than one of these phenomena, or one mechanism could initiate amplification and a second and/or third could be involved during amplification to higher copy numbers.

Substantiating or eliminating any one of these general models has proved to be a difficult task, because amplification of a given chromosomal locus occurs at a frequency of only $10^{-3}-10^{-5}$ per cell generation (Zieg et al. 1983; Stark and Wahl 1984; Tlsty et al. 1989), making it impossible to study initiating events as they occur. Furthermore, the structures of amplicons containing a particular gene differ among different cells in the same selected population and can change with time even at a single drug concentration (see Ardeshir et al. 1983; Federspiel et al. 1984). Thus, it would be advantageous to study initiating events in single cells for in their immediate descendants) to deduce underlying themes.

In recent years it has become possible to examine the chromosomal rearrangements that accompany DNA sequence amplification in single cells by fluorescence in situ hybridization (Pinkel et al. 1986). The sensitivity and resolution of this method allow the detection of single-copy loci with a resolution of a few megabases (Trask 1990).

When we applied fluorescence in situ hybridization (FISH) to an analysis of the early stages of DHFR gene amplification in nine independently derived methotrexate-resistant populations (Trask and Hamlin 1989), several features were noteworthy: (1) in 7 of 9 of these populations (each of which probably arose from only one or two initial events|, both of the original DHFR genes were found at their native $2 \mathrm{q}$ chromosomal locations and appeared to remain single copy; (2) in 6 of 7 of these pop- ulations, the multiple DHFR amplicons were located on the same chromosome arm as one of the original singlecopy loci but usually more than 50 megabase pairs (Mbp) away and sometimes farther out on the chromosome arm than the usual telomere $; 3 \mid$ there were many examples of chromosomal aberrations involving DHFR amplicons, including a very high incidence of dicentric chromosomes or chromosomes displaying sister chromatids fused at their termini 38 of 120 metaphase cells examined).

Similar observations were subsequently made on Syrian hamster cells during the early stages of amplification of the CAD gene in response to PALA selection (Smith et al. 1990), and on Chinese hamster ovary (CHO) cells undergoing amplification of the adenylate deaminase 2 (AMPD2) gene during the acquisition of resistance to coformycin (Toledo et al. 1992). Thus, these features are not unique to a particular cell type or genetic locus.

These data seemed most compatible with an initiating event in which either (1) an unequal exchange occurs between sister chromatids, leading to the transfer of both copies of the DHFR gene to one chromosome arm (as in Fig. 1A); or (2) a transposition/replication event generates additional tandem copies of the gene at some distal position on the same chromosome.

As the diagrams in Figure 1, A and D, show, different chromosomal rearrangements are predicted by each of these mechanisms. For example, in a direct unequal sister chromatid exchange, a large direct repeat is formed; theoretically, no instability would accrue to the cell receiving the extra interstitial material, and no genetic material would be lost from the daughter cell that survives 
selection. In a reverse sister chromatid exchange (equal or unequal), a giant symmetric or asymmetric inverted duplication takes place, with the attendant loss of the material distal to the crossover points on both chromatids (Fig. 1A); the dicentric chromosome thus formed would have to break during the subsequent mitosis, generating frayed ends that could subsequently lead to further dicentrics, translocations, and so forth.

In contrast, a conservative transposition/replication event would lead to a cluster of amplicons separated from the single-copy locus by material that is unrearranged with respect to the original chromosome arm.

It is conceivable that both reverse unequal sister chromatid exchange and conservative transposition/replication could be initiated by the telomere itself, in which case the entire chromosomal arm distal to the singlecopy locus would be duplicated in the initiating event (Trask and Hamlin 1989; Smith et al. 1990).

To discriminate among these models, we have utilized pairs of cosmids from different positions along the $2 \mathrm{q}$ chromosome arm of CHO cells in a two-color FISH analysis of the earliest detectable DHFR gene amplification events. The chromosomal rearrangements observed in this analysis argue strongly that DHFR gene amplification in CHO cells is frequently, if not exclusively, initiated either by chromosome breakage and sister chromatid fusion or by reverse unequal sister chromatid exchange.

\section{Results}

\section{Isolation of probes for the $2 q$ chromosome arm}

Initially, a $\mathrm{CHO}-\mathrm{K} 1$ genomic cosmid library was screened for clones that hybridized to different positions along the $2 \mathrm{q}$ chromosome arm. Three of the clones isolated by this approach $(2 \mathrm{~T} 14,2 \mathrm{~T} 31$, and 2T56) were chosen on the basis of their relatively even distribution along the $2 \mathrm{q}$ arm. Shown in Figure 2, A-C, are examples of the two-color FISH patterns obtained when each of these cosmids was paired with a DHFR-specific cosmid (cH1) and used to probe CHO-K1 cells. The measured positions of each probe on chromosomes 2 and $\mathrm{Z} 2$ were averaged and are diagrammed in Figure 2 (diagram). Note that the $\mathrm{Z} 2$ chromosome has suffered a deletion of part of the $2 \mathrm{p}$ arm but is otherwise identical to chromosome 2 in this cell line (Deavan and Peterson 1973). In both 2 and $\mathrm{Z} 2$, the $2 \mathrm{q}$ arm is $\sim 300 \mathrm{Mbp}$ long (Deavan and Peterson 1973; Trask and Hamlin 1989), and the DHFR, 2T14, 2 T31, and 2T56 markers are $\sim 110,170,210$, and 300 Mbp from the centromere. A third copy of the $2 \mathrm{~T} 56$ probe is also present on the end of an unidentified marker chromosome.

\section{Early amplification events usually involve very large inverted duplications of chromosome $2 q$ sequences}

Nine independent drug-resistant cell populations were isolated by stepwise increases in methotrexate (Trask and Hamlin 1989). Two-color FISH analysis was performed on the least resistant population in each series in which significant numbers of amplificants were detected; these included $\mathrm{CHO} / 0.1$ populations $\mathrm{D}$ and $\mathrm{G}$, and $\mathrm{CHO} / 0.4$ populations $\mathrm{C}, \mathrm{E}$, and $\mathrm{F}$. The remaining four populations were excluded either because (1) the patterns were too complicated to analyze at any drug level (populations $\mathrm{A}, \mathrm{H}$, and $\mathrm{J}$ ), or (2) there was no evidence of amplification (B).

Cells were hybridized with the probe pairs DHFR/ 2T14, DHFR/2T31, or DHFR/2T56, and randomly selected metaphase spreads were chosen for detailed analysis (e.g., see Fig. 3). Photographic slides of these figures were projected onto a digitizing board, and relative centromere, probe, and telomere positions on labeled chromosomes were measured. These values were normalized internally to the $2 \mathrm{q}$ arm of the uninvolved homologous chromosome in the same spread, and the data from the labeled chromosomes were then displayed in outline form as shown in Figure 4 for class E-I and C amplificants.

Inspection of these patterns suggested that most cells examined in a given population arose either from one initial event (as with populations C, D, and F) or from two (as with populations $E$ and $G$ ) (see below). The relative distances among probes, centromeres, and termini within a given class (either one or two per population) were then averaged to produce a summary diagram for each probe and each class (Fig. 5). The model chromosomes in Figure 6 represent a compilation of the data obtained with the three different probes on different sets of cells from the same class.

Note that, within each class of amplificants, the amplicon clusters themselves were quite variable both in pattern and gene copy number (Trask and Hamlin 1989). Here, because we are interested primarily in the arrangement of material between these clusters and the singlecopy DHFR locus, all clusters are represented simply as a box with its length corresponding to the length of the cluster.

A few chromosomes in each population were sufficiently different from the majority to exclude from the averaging procedure. Most of these patterns probably resulted from translocations that occurred concomitant with or after the initial amplification event, obscuring the details of initial sequence rearrangements /see the two on the right in Fig. 4A and in the lower parts of Fig. 4B, Cl.

The most striking findings in this analysis are illustrated by the patterns of hybridization observed with each of the three probe pairs in amplificant classes E-I and $C$ (Figs. 3-6). In class E-I, two pairs of single-copy fluorescent signals from probe $2 \mathrm{~T} 14$ were detected on chromosome $\mathrm{Z} 2$ in the vast majority of spreads (Figs. 3A and $4 \mathrm{~A})$. In all cases, both pairs of the $2 \mathrm{~T} 14$ probe were located between the single-copy DHFR locus and the DHFR amplicon cluster and were approximately the same distance apart. The more distal probe 2T31 gave a pattern similar to $2 \mathrm{~T} 14$, except that the two single-copy 

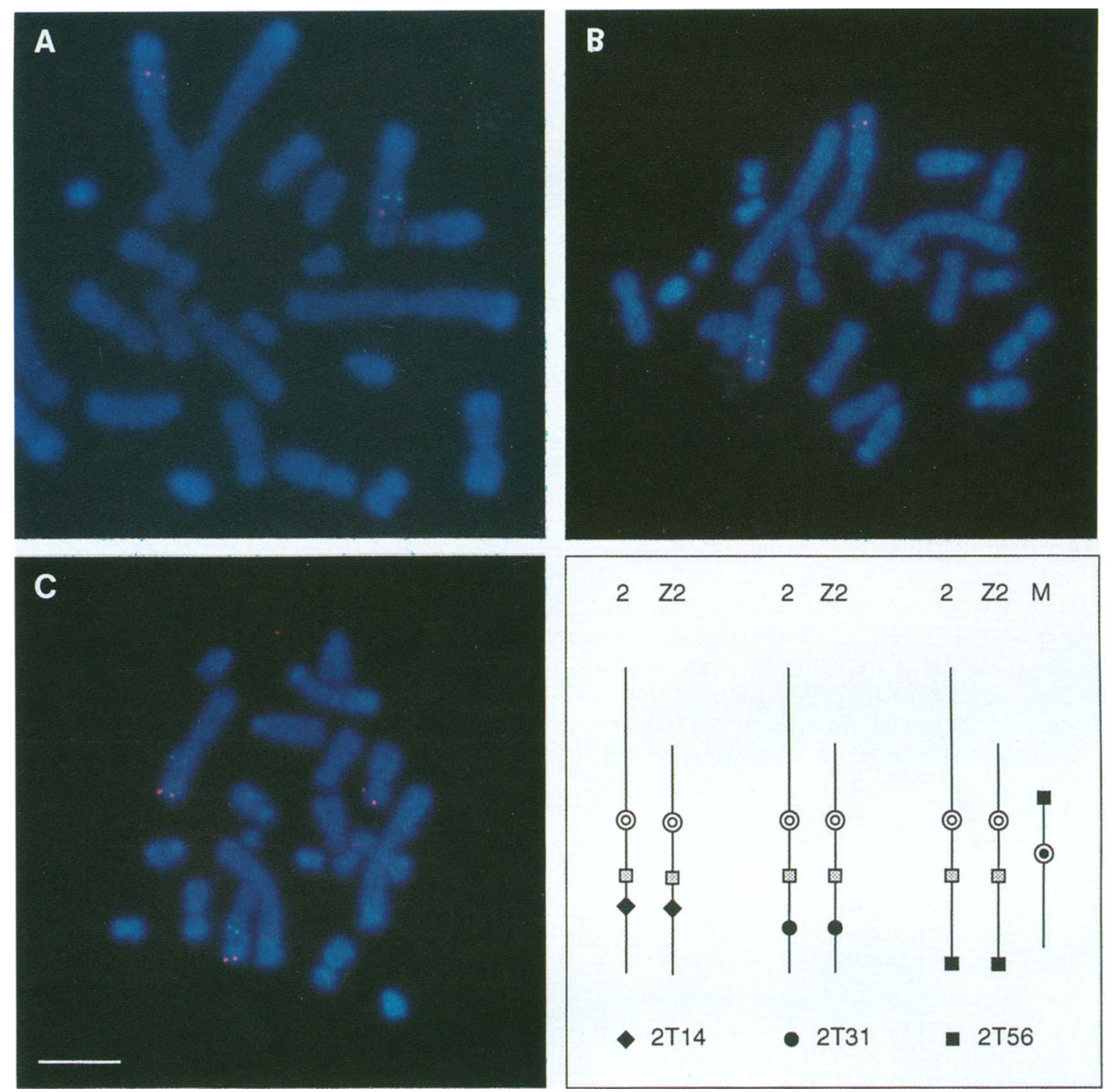

Figure 2. Location of DHFR, 2T14, 2T31, and $2 \mathrm{~T} 56$ on the chromosome $2 \mathrm{q}$ arm. Normal CHO-K1 metaphase cells were simultaneously hybridized with cosmid probes for the DHFR gene (green signals) and 2T14 $(A), 2 \mathrm{~T} 31,(B)$ or 2T56, $(C)$ (red signals). The distances among chromosome termini, centromeres, and probe positions were measured in $>30$ metaphase spreads for each probe pair. The measured distances were normalized to the length of the $2 \mathrm{q}$ arm to correct for differences in chromatin condensation among spreads. The diagram summarizes the relative positions of each probe. Note that a third copy of the 2T56 sequence is present near the tip of the short arm of a marker chromosome (M). (O) $2 / 22$ centromere; (O) marker chromosome centromere; ( $\square$ ) DHFR gene. Bar, $10 \mu \mathrm{m}$.

2T31 signals were much closer together (Figs. 3B and 4B). In contrast, probe $2 \mathrm{~T} 56$, which is very near the terminus of chromosome 2, was not detected on any ampliconbearing chromosome in any class of amplificants (see
Figs. 3C,F, and 6). It is clear from the summary diagram for class E-I in Figure 6 that a giant inverted duplication has occurred between the single-copy DHFR locus and the terminal DHFR amplicon cluster.

Figure 3. Examples of two-color FISH analyses of populations E-I and C. Metaphase cells from populations E and C were hybridized with the DHFR gene (green signals) and 2T14, 2T31, or 2T56 (red signals). The chromosomes were counterstained with DAPI. (A) A class E-I cell probed with DHFR/2T14; note the double set of 2 T14 signals between the single-copy DHFR locus and the amplicon cluster. (B) A class E-I amplificant with DHFR/2T31; note the double set of 2 T31 signals between the DHFR locus and the amplicon cluster; also note the fused termini. $(C)$ A class E-I cell probed with DHFR/2T56; 2T56 is present on chromosome 2 and the marker chromosome, but is absent from the amplicon-bearing Z2 chromosome. $(D)$ A class C amplificant probed with DHFR/2T14; a double set of $2 \mathrm{~T} 14$ signals is not only detected between the DHFR locus and the amplicon cluster but also between the two amplicon clusters on chromosome 2. (E) A class C cell with DHFR/2T31; two pairs of 2 T31 signals are detected between the DHFR locus and the first amplicon cluster but are not present between amplicon clusters. $(F)$ A class C amplificant with DHFR/2T56; 2 T56 is absent from the amplicon-bearing chromosome 2 . Bar, $10 \mu \mathrm{m}$. 


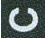
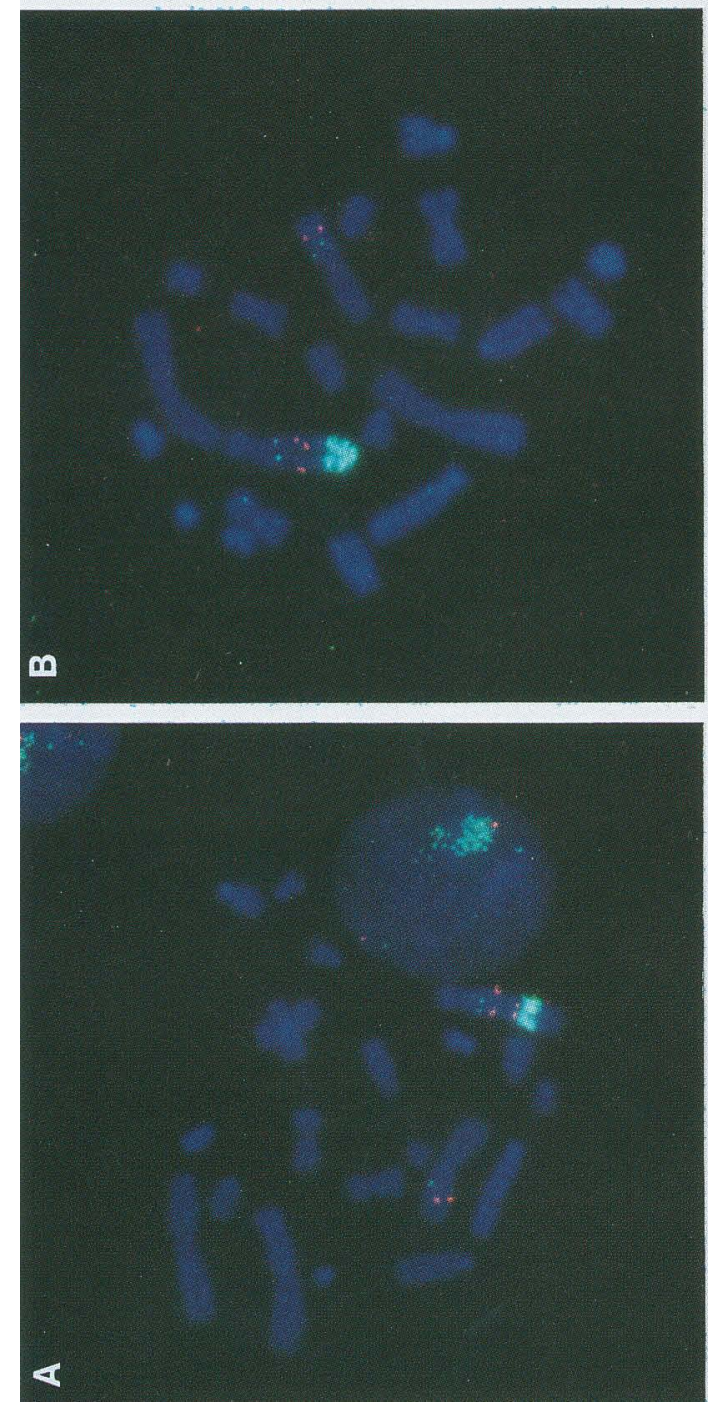
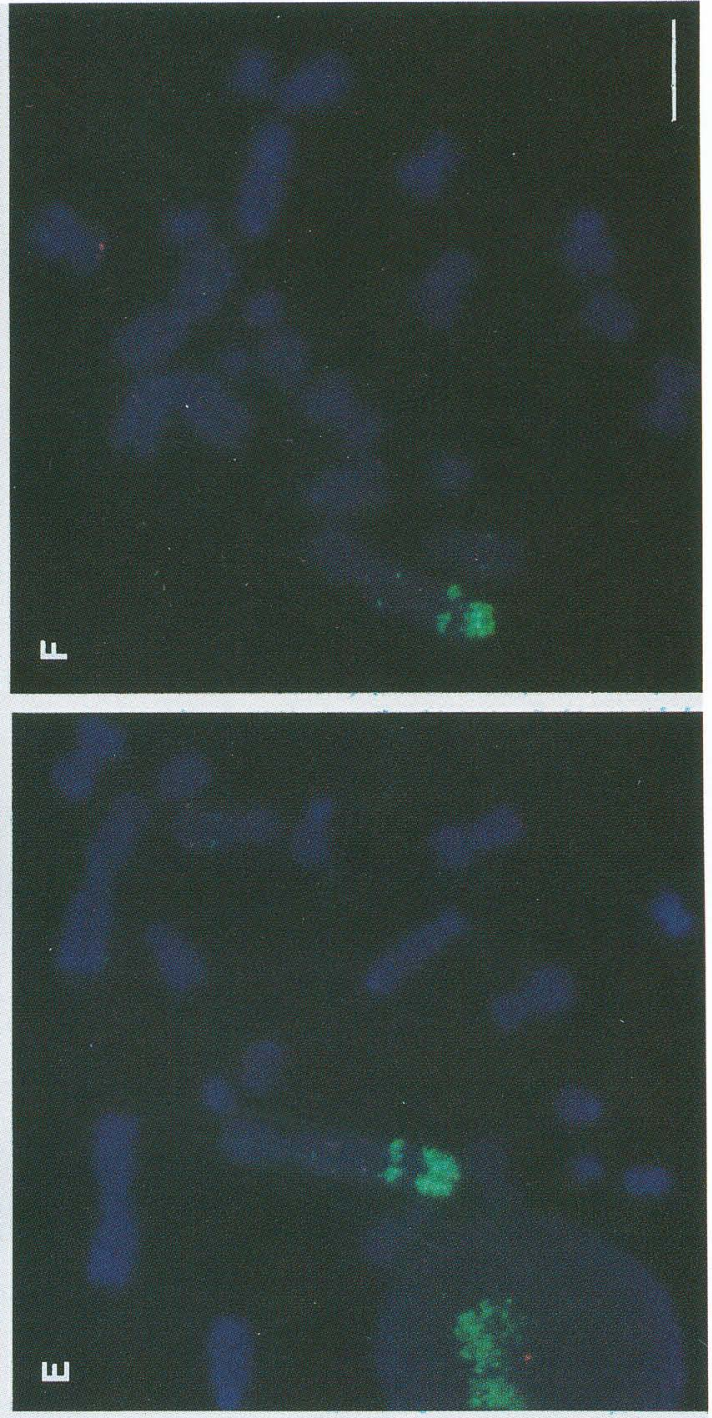

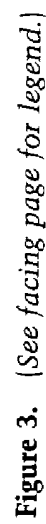

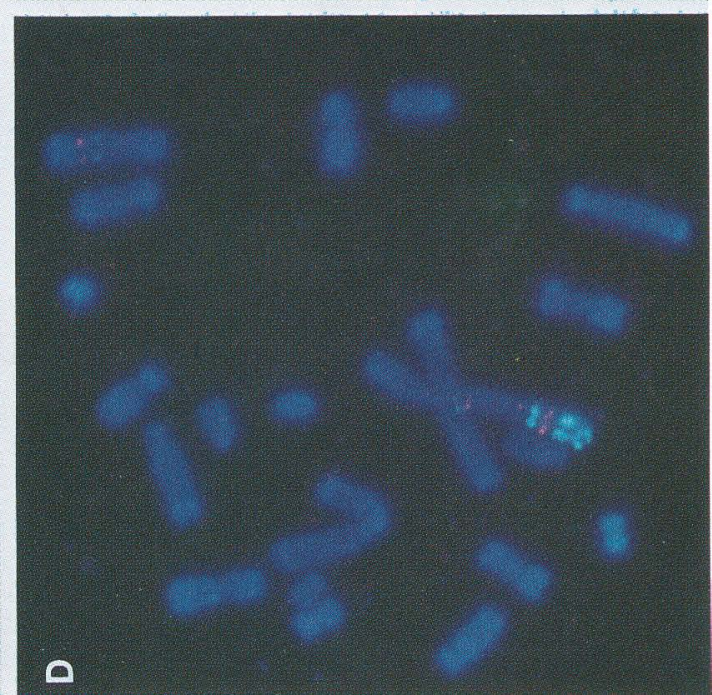




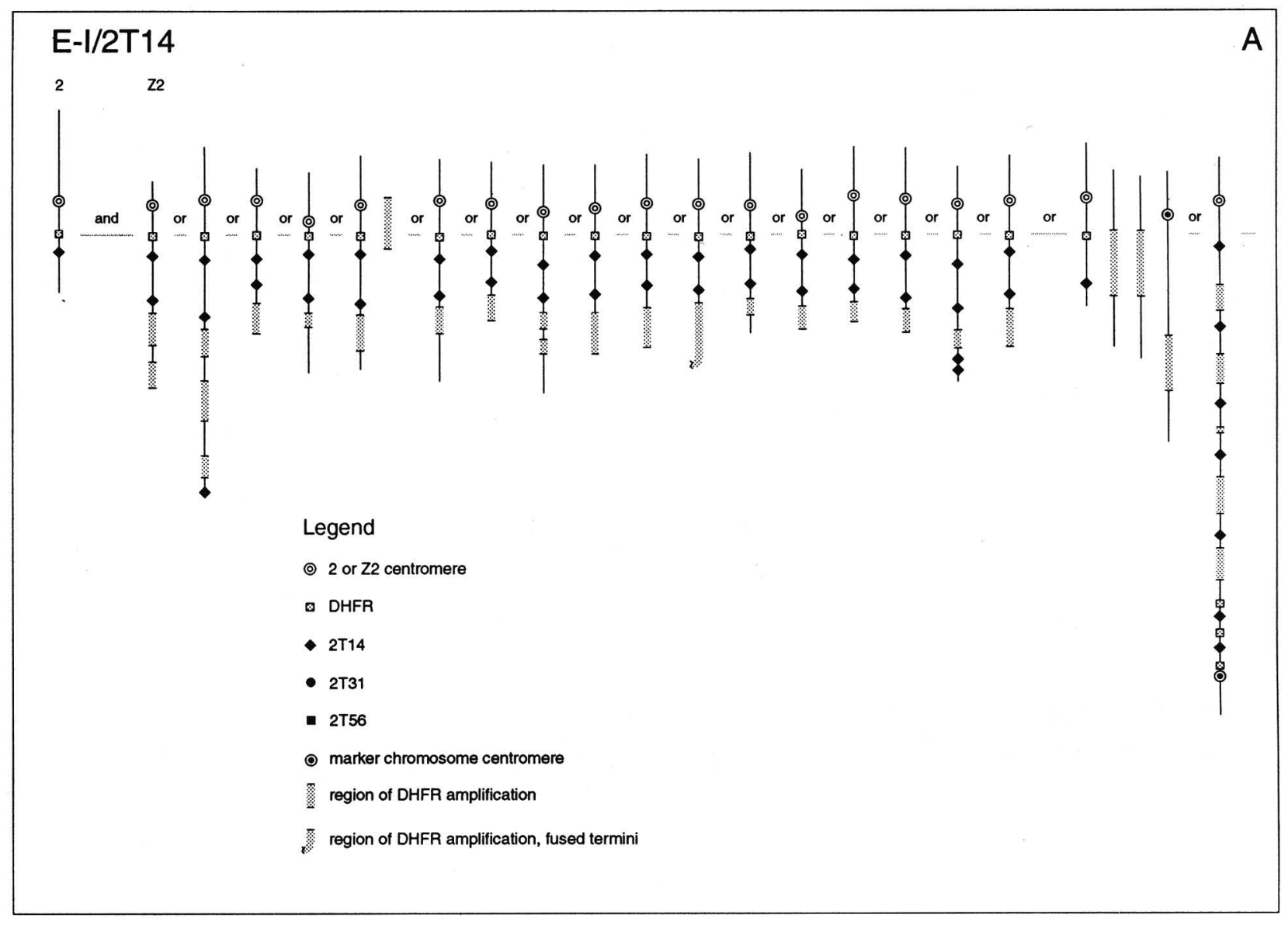

\footnotetext{
$\mathrm{E}-\mathrm{I} / 2 \mathrm{~T} 31$

$2 \quad \mathrm{Z2}$

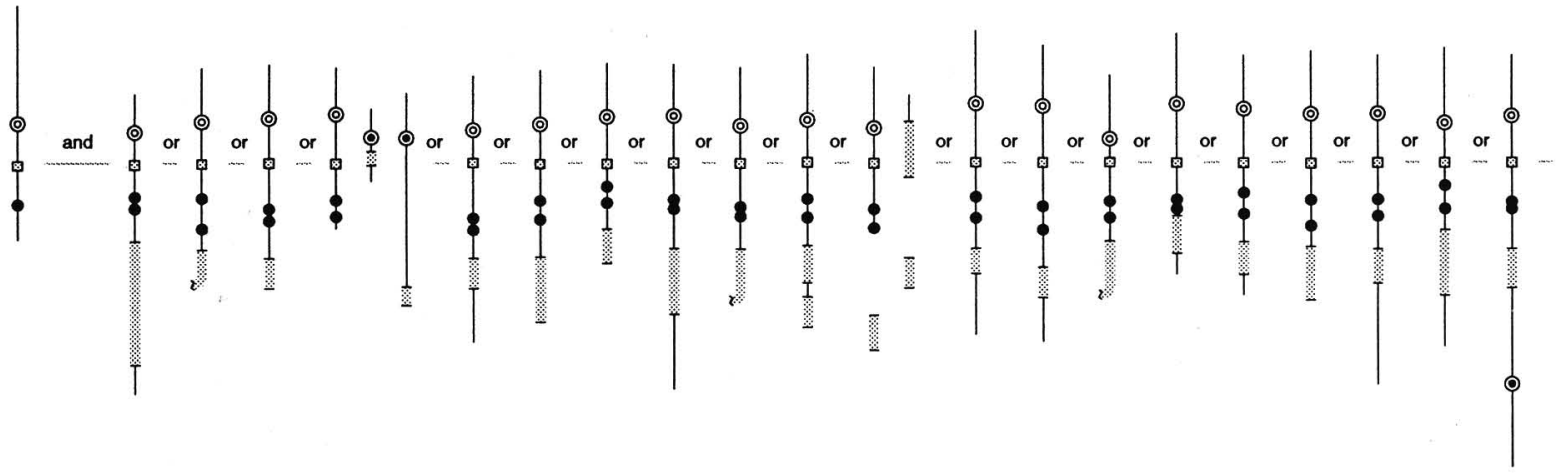$$
\text { or or }
$$

Figure 4. Summaries of FISH patterns on class $E-I$ and $C$ amplificants. After two-color FISH, the positions of centromeres, the DHFR gene, the $2 \mathrm{~T}$ probes, and amplicon clusters were determined in several randomly selected metaphase spreads of each class. Measured distances were normalized to the length of the unaffected 2q arm. $(A)$ Chromosomes from class E-I probed with DHFR/2T14 (19 of 28 analyzed cells in population E; the remaining 9 cells were classed as E-II on the basis of the presence of a single 2T14 site between the DHFR locus and the amplicon cluster). (B) Chromosomes from class E-I hybridized with DHFR/2T31 (22 of 33 analyzed cells in population $\mathrm{E}_{\text {; }}$ the remaining 11 cells were classified as E-II). (C) Chromosomes from class $\mathrm{E}$ probed with DHFR/2T56 (25 of 25 analyzed). $(D)$ Chromosomes from class C probed with DHFR/ 2 T14 ( 27 of 27 analyzed). Although the amplicon clusters within a population or class could be patchy or homogenous, they are collectively represented by the same symbol (shaded areas). (4C) Tetraploid cell; (M) the marker chromosome that normally hybridized to 2T56 is not present; (ER) endoreduplicated chromosomes (four aligned chromatids) with a given pattern.
} 

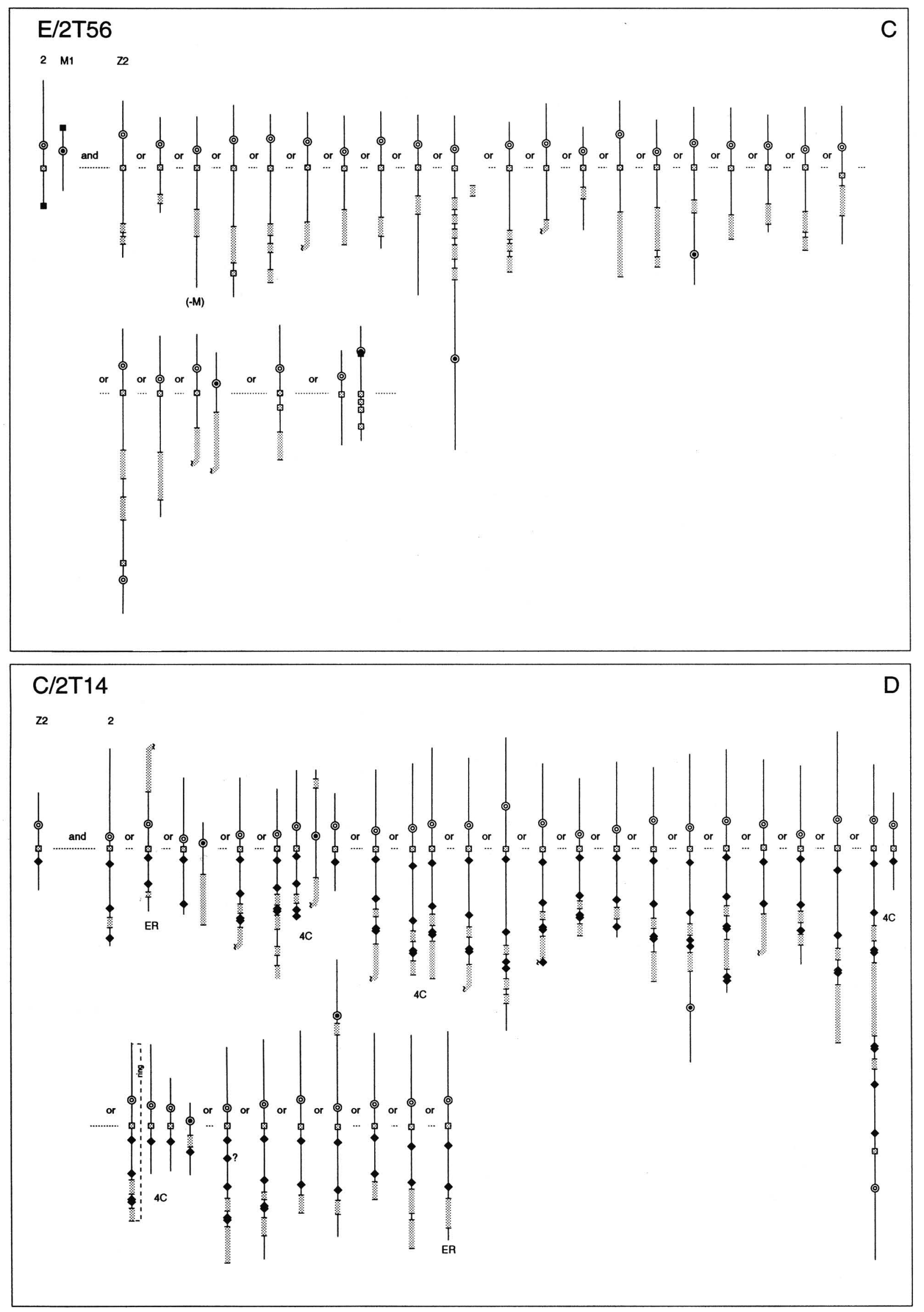

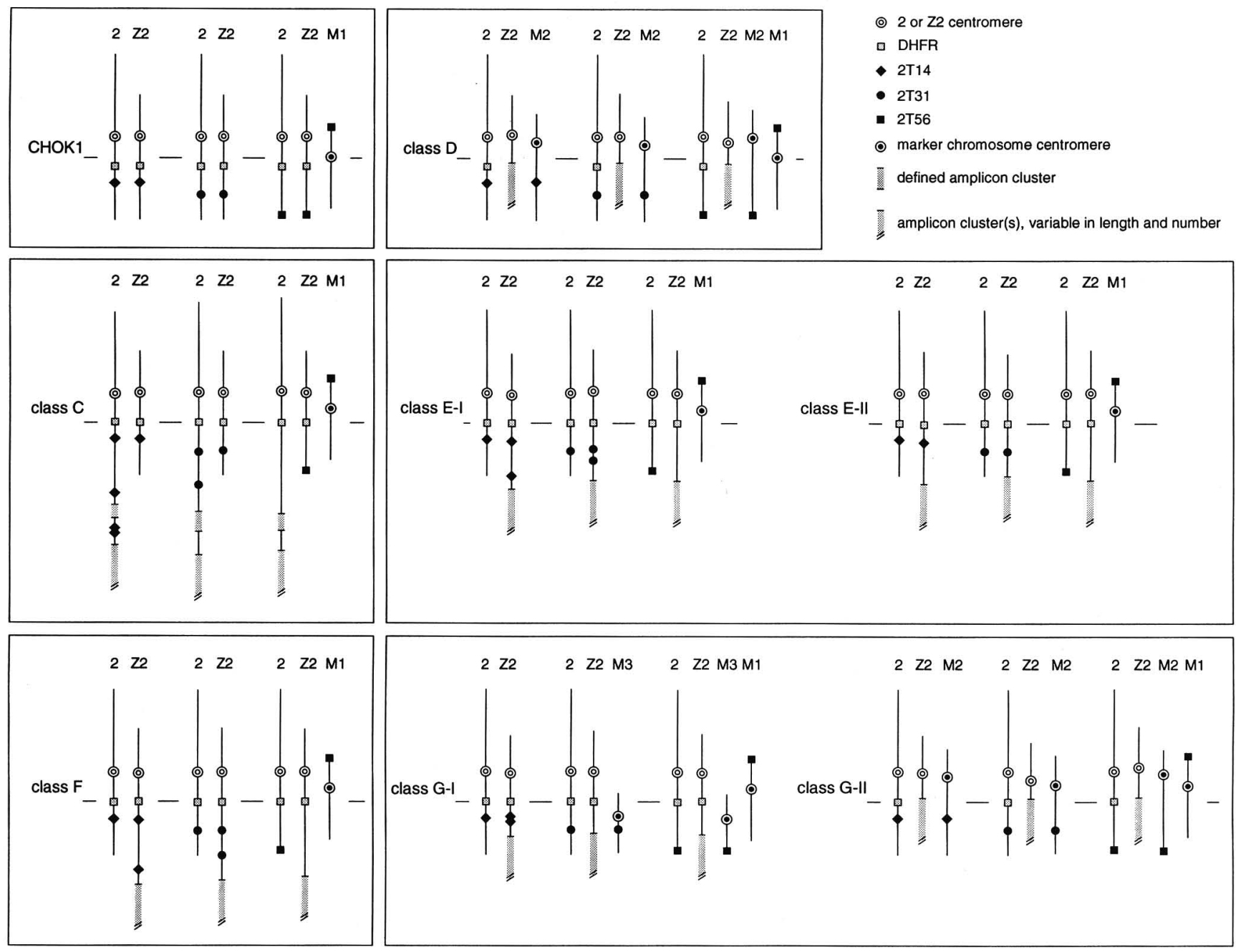

Figure 5. Averaged hybridization patterns for the $2 \mathrm{~T} 14,2 \mathrm{~T} 31$, and $2 \mathrm{~T} 56$ probes on all amplificant classes. Normalized distances among centromere, DHFR, $2 \mathrm{~T}$ probes, amplicon clusters, and termini were averaged for all chromosomes within each amplificant class. The consensus chromosomes shown here were drawn using these average distances. For example, for class E-I, measurements from 17 chromosomes labeled with DHFR/2T14/the first 17 shown in Fig. 4A/ were averaged to produce the drawings of chromosomes 2 and $\mathrm{Z} 2$ shown in the center. For all other probes and classes, measurements from 15-39 chromosomes were averaged to compile the consensus chromosomes shown, except for classes C (probe 2T31), G-II, and E-II. For these classes, measurements from only 4-11 chromosomes could be obtained. With the exception of a defined amplicon cluster in class $C$ (Figs. 5 and 6), the amplicon clusters varied among chromosomes within the same class in length, number, and status of their termini (i.e., fused or not; e.g., the terminal amplicon clusters in Fig. 3). Therefore, the amplicon clusters are collectively represented here by the same symbol (a shaded area terminated by double diagonal lines).

Class $\mathrm{C}$ displayed many of the characteristics of class E-I: Probes 2 T14 and 2T31 were again present as doublets in an even larger inverted duplication (Figs. 3D,E, $4 \mathrm{D}, 5$, and 6). When compared with the uninvolved $2 \mathrm{q}$ chromosome arm (Fig. 6), it is also apparent that because of the presence of this duplicated material, the DHFR amplicons in class $C$ are situated at a greater distance from the centromere than the usual end of the chromosome (as they also are in classes F, E-I, and E-II).

Interestingly, additional copies of probe $2 \mathrm{~T} 14$ (but not 2T31) were present on chromosome 2 in most of the spreads, usually appearing as a doublet between two small amplicon clusters (Figs. 3D, 4D, 5, and 6). Thus, in class $\mathrm{C}$, it appears that an initial inverted duplication was followed by a subsequent inverted duplication involving only a fraction of the original unit isee Discussion). At some point, however, amplification of very small units must have occurred, to account for the presence of the homogenous, brightly staining amplicon clusters between these smaller palindromes (Fig. 4D).

As with class E-I, the most distal probe (2T56) was not detected on any of the amplicon-bearing chromosomes in class $\mathrm{C}$ (Fig. 3F, 5, and 6).

The diagrams in Figure 5 summarize the two-color FISH data obtained with each of the three probe pairs on all of the seven amplificant classes that were analyzed in 


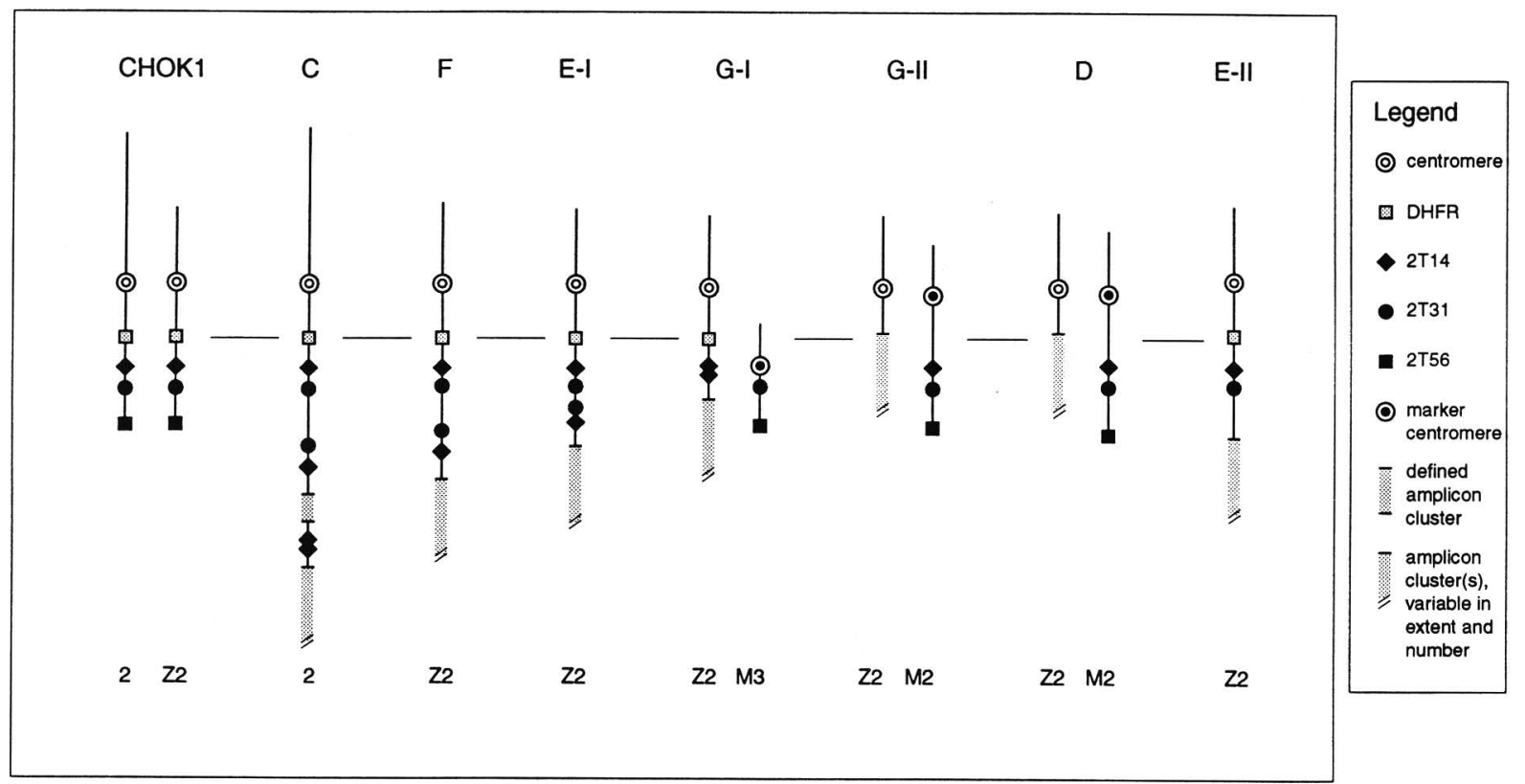

Figure 6. Model chromosomes from each amplificant class. The averaged distances between chromosome features (centromere, probes, amplicon cluster boundaries, and termini) were compiled to produce model chromosomes for each class. Although the three $2 \mathrm{~T}$ probes were not hybridized simultaneously to cells, the distances obtained with each probe individually (Fig. 5) were consistent with the combined patterns shown here. Both chromosomes are shown for normal CHO-K1 cells. The marker chromosome (M1), whose short arm hybridized with $2 \mathrm{~T} 56$ in $\mathrm{CHO}-\mathrm{Kl}$ and all of the variants, as well as the unaffected chromosome in the amplificants ( $\mathrm{Z} 2$ in class $\mathrm{C}$ and 2 in all the other classes) are omitted for simplicity.

detail. The data for all three probe pairs are combined to produce the model chromosomes for each class shown in Figure 6.

In five of the seven independent classes $\mid \mathrm{C}, \mathrm{F}, \mathrm{E}-\mathrm{I}, \mathrm{G}-\mathrm{I}$, and E-II), the single-copy DHFR locus is present at its original location and remains single copy. A large but variably sized inverted duplication has occurred on the $2 \mathrm{q}$ chromosome arm in the initial progenitors of class $\mathrm{C}$, F, E-I, and G-I amplificants. In each of these cases, the inverted duplication could be interpreted to be symmetrical. Note that probe $2 \mathrm{~T} 14$ is included in the smaller inverted duplication in class G-I amplificants, but the more distal 2T31 marker is not; nevertheless, the 2T31 marker appears as a translocation on another small chromosome (Fig. 6). Examples of the FISH patterns obtained with probe pairs DHFR/2T14 and DHFR/2T31 on class G-I are shown in Figure 7,A and B /the white arrow in Fig. $7 \mathrm{~B}$ indicates the translocation chromosome).

Classes G-II and D are remarkably similar in their hybridization patterns, and both appear to represent in loco amplification events (Fig. 6). In both cases, however, the end of the $2 q$ arm distal to the DHFR gene has been translocated to an unidentified marker chromosome (an example of the DHFR/2T14 FISH pattern on a class D amplificant is shown in Fig. $7 \mathrm{C}_{\text {; }}$ the white arrow indicates translocation). This translocation was confirmed using 2T25, a marker that lies only 5-10 Mbp distal to the DHFR gene in CHO-K1 cells (Fig. 7E). Despite its proximity to DHFR, $2 \mathrm{~T} 25$ is absent from $\mathrm{Z} 2$ in class D amplificants and has also been translocated to the marker chromosome (white arrow, Fig. 7F).

Class E-II (Figs. 5, 6, and 7D) is unique in that an inverted duplication is not apparent from the patterns of hybridization, yet the amplicon clusters in this class are nevertheless farther out on the chromosome than the usual telomere (compare with the normal 2 and $\mathrm{Z} 2$ chromosomes to the left in Fig. 6). The origin of the additional material between the 2T31 marker and the DHFR amplicon clusters is therefore not immediately obvious (but see Discussion). [Note that a class E-I amplificant was present in the same field in the upper left hand corner of Fig. 7D (white arrow).]

Remarkably, 93 of the 381 mitotic figures $(24 \%)$ examined in this study displayed fused termini, in each case involving an amplicon cluster \{e.g., as in Figs. 3B and $7 D)$. In addition, 22 mitotic cells $(6 \%$ of the total $\}$ displayed dicentric chromosomes containing amplicon clusters.

\section{Discussion}

The most important generalizations that can be made from this study are as follows: (1) DHFR amplicons are on the $2 q$ chromosome arm in 9 of 10 amplificant classes (A is the exception). (2) Except for classes G-II and D, the amplicons are very far away from the single-copy DHFR locus and usually occupy terminal positions on the chromosomes. (3) The region between the single-copy locus 
Ma et al.
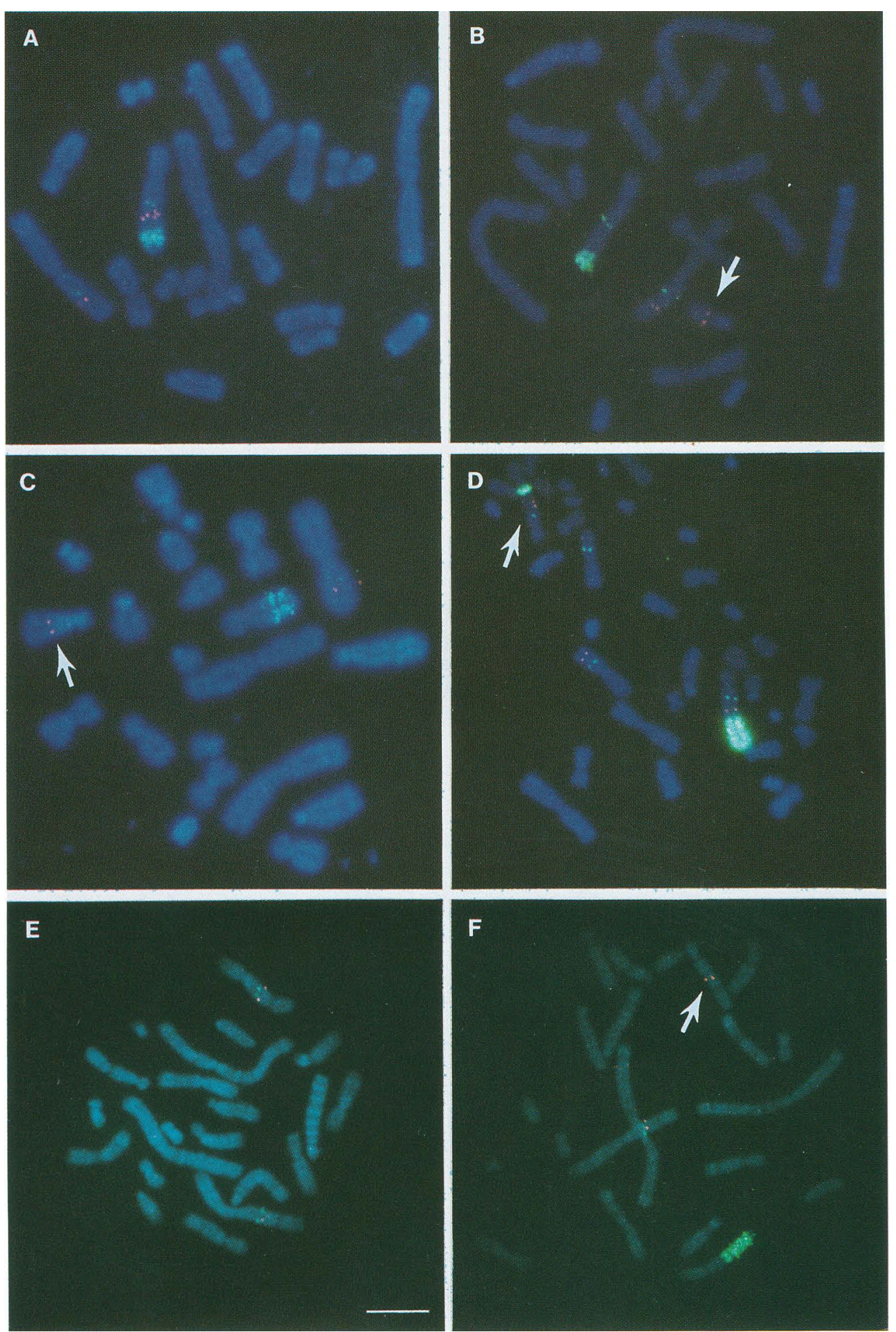

Figure 7. Selected FISH patterns from amplificant classes G-I, D and E-II. (A) A class G-I cell probed with DHFR/2T14; two closely spaced pairs of 2 T14 signals are detected between the DHFR single-copy locus and the amplicon cluster. $(B)$ A class G-I cell probed with DHFR $/ 2$ T31; 2T31 cannot be detected between the DHFR single-copy locus and the amplicon cluster on chromosome Z2 but has been translocated to a marker chromosome (white arrow). (C) A class D cell probed with DHFR/2T14; the amplicon cluster is unresolved from the site of the DHFR single-copy locus, and $2 \mathrm{~T} 14$ has been translocated from Z2 to a marker chromosome (white arrow). $(D) \mathrm{A}$ class E-II cell probed with DHFR/2T31; a single pair of $2 \mathrm{~T} 31$ signals is present between the DHFR locus and the amplicon cluster, which is involved in a terminal fusion; note the class E-I cell with two pairs of $2 \mathrm{~T} 31$ signals (upper left; white arrow). (E) CHO-K1 cells hybridized with DHFR and 2T25, a cosmid probe that maps close to but distal to the DHFR gene. $|F|$ A class D cell probed with DHFR/2T25; 2 T25 is not present on the amplicon-bearing $\mathrm{Z} 2$ chromosome but has been translocated to a marker chromosome /white arrow). Bar, $10 \mu \mathrm{m}$. 
and the DHFR amplicon clusters represents a duplication of material that appears to derive exclusively from the chromosome $2 \mathrm{q}$ arm itself, because probes $2 \mathrm{~T} 14 \mathrm{al}$ ways and $2 \mathrm{~T} 31$ usually hybridize to this intervening region. (4) These large duplications are inverted in at least 4 of 7 amplificant classes studied in detail here (C, F, E-I, and G-II, and possibly in all of them (see below); the duplications can be interpreted as being symmetrical in classes C, F, E-I, G-I, G-II, and D. (5) The telomere-proximal 2T56 probe was never included in the duplication in the amplificants studied here. (6) Markers distal to 2T31 that are not included in the duplications appear to be lost from the cell (Fig. 6, classes C, F, E-I, and E-II); however, when $2 \mathrm{~T} 31$ is excluded from the duplication (as in classes G-I, G-II, and D), the entire chromosome end from at least 2T31 outward appears on a second, unrelated chromosome. (7) In some cases, markers distal to the DHFR gene that are included in the initial amplification are repeated between amplicon clusters [e.g., $2 \mathrm{~T} 14$ in class $\mathrm{C}$ (Fig. $3 \mathrm{D}$ ) and $2 \mathrm{~T} 25$ in classes $\mathrm{C}$ and $\mathrm{F}$ [data not shown)].

These observations can be explained by a single general model for initiation of amplification involving the generation of a dicentric chromosome. According to one version of this model (Fig. 8), a chromosome breaks somewhere along the $2 \mathrm{q}$ arm at a position distal to the DHFR gene. If the break occurs on an unreplicated chromosome (model A, step 1), the frayed chromosome end that is generated could fold back on itself to form a hairpin (possibly at palindromic sequences; step 2). Any gaps could be filled, the two helices could be fused by ligation, and the chromosome could be replicated to form a dicentric (step 3). If the break occurs on an already replicated chromosome (model B), the ends of the two double helices (chromatids) could fuse to one another by related hybridization and repair mechanisms to form a dicentric (steps 1-3).

The immediate outcome of the terminal fusion would be the formation of a giant, nearly symmetrical inverted duplication whose center of symmetry corresponds approximately to the position of the original breakpoint. After centromere duplication and separation, the dicentric chromosomes will suffer another break somewhere between the two centromeres during the subsequent mitosis, generating two chromosomes with frayed ends (step 4), but only those breaks occurring between the DHFR gene and the nearest centromere would transfer both copies of the gene to one chromosome.

An alternative route to forming a dicentric could be a reverse unequal sister chromatid exchange in which a giant asymmetric inverted duplication occurs (Fig. 8, model Cl, attended by the loss of different amounts of material from each chromatid end (step 1).

The apparently symmetrical arrangement of the duplicated single-copy markers displayed by amplificant classes C, F, E-I, and G-I argue for the operation of the symmetrical breakage/terminal fusion mechanism. In the absence of probes situated very close to the breakpoint in each case, however, it is not possible to discriminate between this mechanism and an asymmetric re-

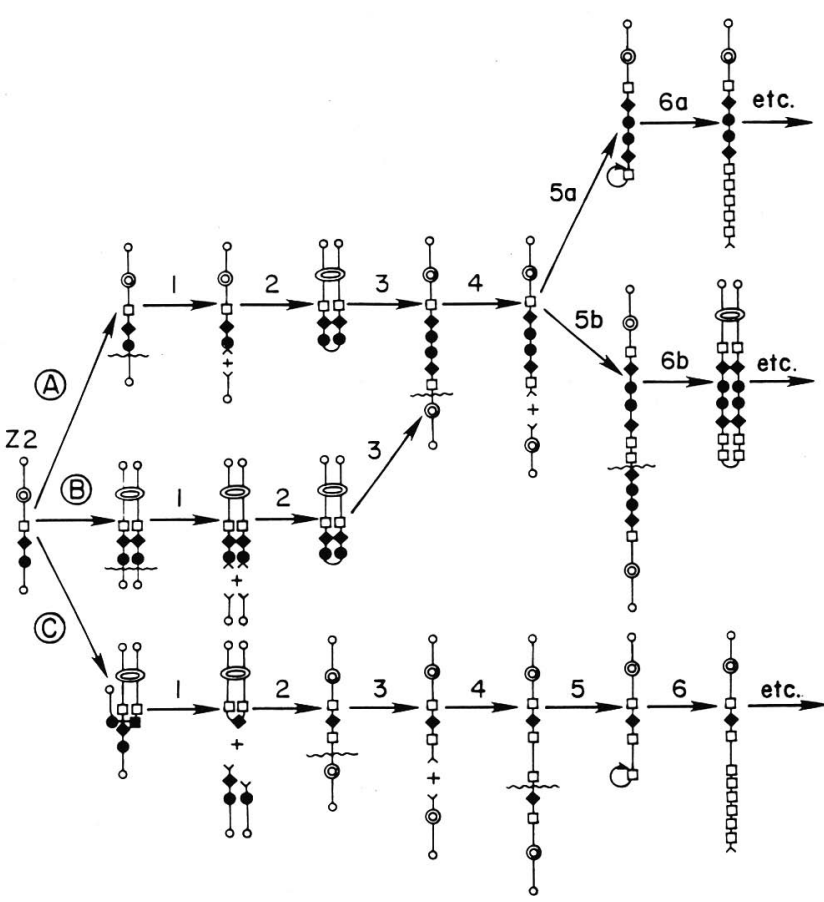

Figure 8. Proposed mechanisms for initiating amplification of the DHFR locus in CHO cells. In this diagram a single line is equivalent to a double helix, telomeres are denoted by the small open circles, and frayed ends are indicated with a Y symbol. The other symbols are those employed in Figs. 2, 4, 5, and 6. (Model A) The unreplicated chromosome (Z2 in this case) suffers a break distal to the $2 \mathrm{~T} 31$ marker (step 1), followed by terminal fusion, either by repair or during the subsequent $\mathrm{S}$ period /step 2). The resulting dicentric then breaks between one centromere and a DHFR gene (step 4), resulting in the transfer of both copies of the DHFR gene to one chromatid, which now has a frayed end. The near-terminal DHFR gene can now be amplified by a roll-in replication mechanism (step 5a). Alternatively, the frayed ends can fuse again to form a dicentric (step 5b), which then breaks asymmetrically again to transfer all four copies of the DHFR gene to one chromatid (step 6b), etc. (Model B) The replicated $\mathrm{Z} 2$ chromosome breaks at the same place on both chromatids (step 1), the ends fuse (step 2), and the bridge/breakage/fusion cycle continues as in model A (step 3). (Model C) An asymmetrical reverse sister chromatid exchange takes place below the $2 \mathrm{~T} 14$ marker on one chromatid but above $2 \mathrm{~T} 14$ on the other (step 1). This results in the formation of a dicentric chromosome with an asymmetric inverted duplication (step 2). This dicentric chromosome then breaks between one DHFR gene and a centromere (step 3), transferring both copies of the DHFR gene to one chromosome. Terminal fusion of the frayed ends then occurs (step 4), leading to subsequent bridge/breakage/fusion cycles, possibly interspersed with roll-in replication cycles (step 6).

verse unequal sister chromatid exchange (particularly in class $\mathrm{C}$ and $\mathrm{F}$ amplificants, in which the region between the two $2 \mathrm{~T} 31$ probes is so largel.

In the case of class G-I (Fig. 6), in which the break occurred centromere-proximal to the $2 \mathrm{~T} 31$ probe, the remainder of the chromosome (i.e., material carrying the $2 \mathrm{~T} 31$ and $2 \mathrm{~T} 56$ markers) has been translocated to a 
marker chromosome apparently intact /note that the two probes are the same distance apart as on the normal $2 q$ arms; Fig. 6). Thus, some of the genetic loci lost from the $2 q$ arm during the duplication event must be required in two copies to maintain cell viability independent of methotrexate selection pressure per se.

This interpretation is strengthened by class G-II and D amplificants, in which the amplicon cluster appears to be located close to the usual single-copy DHFR site and the remainder of the chromosome /this time including the 2T14, 2T31, and 2T56 markers| has been translocated to a marker chromosome (Figs. 5-7). This, in turn, suggests that the class G-II and D amplificants have also suffered a break very close to the single-copy locus, which then leads to the requisite dicentric as well as the acentromeric chromosome fragment that is subsequently translocated to the marker. This hypothesis is strengthened by two additional observations: (1) the 2T25 marker, which maps very close to the DHFR gene on the distal side, is also translocated to the marker chromosome in class D amplificants (Fig. $7 F$ ); and (2) the region distal to the amplicon cluster on some chromosomes in class $\mathrm{D}$ appears to be an inverted duplication of material proximal to the single-copy DHFR locus (this was demonstrated with probe $2 \mathrm{~T} 57$, which maps between the DHFR gene and the centromere; data not shown).

In class E-II amplificants, the nonsymmetric arrangement of the single-copy hybridization probes argues that a reverse unequal sister chromatid exchange may have taken place.

Thus, the hybridization patterns detected in all of the amplificant classes examined here can be explained either by (1) a symmetric chromosome break that occurs either before or after chromosome replication, followed by fusion of the frayed ends of the two chromatids (classes C, F, E-I, G-I, G-II, and D); or (2) a reverse unequal sister chromatid exchange (i.e., an asymmetric break on the two chromatids after replication, followed by fusion of the two ends, as in class E-II). Many examples of the fused intermediates predicted by this breakage/terminal fusion model were actually observed in these studies $(24 \%$ of spreads; e.g., see Figs. $3 \mathrm{~B}$ and $7 \mathrm{~F})$, as well as large numbers of dicentric chromosomes $16 \%$ of spreads; e.g., see Fig. 4). It is also interesting to note that several examples of inverted duplications have been observed in the smaller amplicons that characterize cell lines with high amplicon copy numbers (e.g., see Ford and Fried 1986; Looney and Hamlin 1987; Ma et al. 1988; Hyrien et al. 1989). In each of these examples, however, the palindromic junctions are amplified, and they are relatively close to the selected gene. It is therefore unlikely that they correspond to the original breakage/fusion joint formed during the initiation event. More likely, they represent junctions formed during later bridge/breakage/fusion cycles (as in steps $5 \mathrm{~b}$ and $6 \mathrm{~b}$ (model A) in Fig. 8).

Is it possible to explain the patterns observed in these drug-resistant variants by other models? As we have argued before (Trask and Hamlin 1989), the deletion/epi- some model (Fig. 1C; Wahl 1989) is untenable, because the single-copy loci are retained at their native positions in virtually all of the amplificant classes examined here (classes G-II and D being indeterminant). In a previous single-color in situ hybridization analysis, we utilized a probe consisting of eight cosmids representing $\sim 270 \mathrm{~kb}$ of DNA including and surrounding the DHFR gene. It has therefore been suggested that the gene itself might have been deleted to form an episome but that other neighboring sequences remaining at the deletion site would still be detected by the mixed probe (Windle et al. 1991). In this study we used a single DHFR-specific cosmid in which the gene occupies $>95 \%$ of the insert. Therefore, it is clear that in the cell populations examined here, the single-copy DHFR gene remains at its native location after initial amplification events have occurred.

Re-replication followed by in loco integration (Fig. 1B) also can be ruled out as a common mode of initiating amplification of the DHFR gene, because only in class G-II and D amplificants are the amplicons near the original single-copy locus (Fig. 6). As argued above, the relatively precise transfer of the chromosomal material distal to the DHFR gene onto another chromosome suggests that in this case, too, a break has occurred near the gene, generating both a dicentric and a transient acentromeric fragment. If the re-replication model is extended to include integration of the extra copies at other sites, it must still be explained why the reintegration usually occurs on the $2 q$ arm at the chromosome terminus and why it is separated from the single-copy locus by large amounts of inverted chromosome 2 material.

Roll-in replication (Fig. 1D), which characterizes some forms of conservative transposition in bacteria /Galas and Chandler 1981; Harshey and Bukhari 1981), can also be ruled out as an initiating event on formal grounds, because the large inverted duplications observed in most amplificant classes could not be replicated by one fork in a single cell cycle [at a fork rate of $3 \mathrm{~kb} / \mathrm{min}$ (Huberman and Riggs 1972), a maximum of $\sim 1$ Mbp could be replicated in an 8-hr S period]. By the same arguments, rolling-circle replication cannot easily account for subsequent amplification steps in which repeating units appear to be megabases in length (e.g., Fig. 3D; Trask and Hamlin 1989; Smith et al. 1990; Toledo et al.; 1992). Furthermore, it is not obvious how a roll-in replication mechanism could result in amplicon clusters situated at a position distal to the usual terminus.

There is one aspect of the early stages of amplification, however, in which some version of roll-in replication may play a role, at least in hamster cells. In the class E-II pattern shown in Figure 3A, for example, the individual DHFR amplicons in the cluster are clearly quite small relative to the original inverted duplication. Perhaps these amplicons could have arisen at a later stage by rolling circle replication (see below).

A plausible chain of events that could explain our observations is outlined in Figure 8. A dicentric chromosome is formed by the postulated initial break or reverse unequal exchange, followed by terminal fusion (models 
$\mathrm{A}$ and B). During the subsequent mitosis, this dicentric then breaks between one DHFR gene and its proximal centromere, generating a chromosome with a large symmetric or asymmetric inverted duplication and a frayed end (step 4). The other daughter cell would undoubtedly die in the presence of methotrexate owing to the loss of the DHFR and other genes.

The frayed ends could again fuse (Fig. 8, model A, step $5 \mathrm{~b}$ ), resulting in the formation of a symmetrical dicentric chromosome with four copies of the DHFR gene and two centromeres. A subsequent asymmetric break could then transfer all four copies to one chromatid, which again would have an unstable frayed end (step 6 b). This end could then initiate another cycle of breakage and fusion leading to another inverted duplication, and so forth.

At some point, such a frayed end could initiate roll-in replication by invading the same chromatid above the DHFR gene (Fig. 8, model A, step 5a). After some number of cycles of rolling circle replication around the template loop (which would presumably be quite small), the resulting homogenous amplicon cluster could become fused with the end of the other broken chromatid for with its own end) to generate another dicentric chromosome. The two events (roll-in replication and dicentric formation/ could possibly alternate in successive cell cycles, accounting for patterns such as those observed in class $\mathrm{C}$ amplificants (Figs. 4D and 6).

Amplificants surviving each round of selection will probably be those in which the units of amplification become increasingly small, because there will be a limit on the amount of extra chromosomal material that a mitotic chromosome can easily tolerate without breakage and loss. This may explain why homogenous clusters of smaller repeating units are observed very early during the amplification process (Figs. 3 and 7; Trask and Hamlin 1989; Smith et al. 1990; Toledo et al. 1992/.

The possibility that bridge/breakage/fusion cycles could be involved in the early stages of DNA sequence amplification was suggested previously to explain the high frequency of dicentric chromosomes in cell lines that had amplified a transfected DHFR gene (Kaufman and Sharp 1982), and was based on the original observations of McClintock (1941) on genetic instability in corn. On the basis of FISH analysis of CAD gene amplification in baby hamster kidney cells, Smith et al. $(1990,1992)$ proposed that an early event might involve fusion of two telomeres to form a dicentric chromosome. The failure to detect the telomere-proximal $2 \mathrm{~T} 56$ probe in any of the duplications detected in the present study would appear to rule out this particular model for initiating events at the DHFR locus.

Toledo et al. (1992) have also utilized two color FISH analysis to study early events in the amplification of the AMPD2 gene in Chinese hamster fibroblasts. In addition to the AMPD2 probe, they chose a second marker located several megabase pairs closer to the centromere on chromosome 1. An analysis of several cloned coformycin-resistant variants showed that this second marker is often coamplified with AMPD2 in large inverted repeats on chromosome 1. Toledo et al. also proposed that bridge/breakage/fusion cycles could mediate early steps in gene amplification. We suggest that had they used a centromere-distal (as opposed to proximal) probe in combination with AMPD2, they would have detected the initial formation of a large inverted duplication such as that observed in this study.

Why does amplification only occur in tumor cells? Are they more prone to the chromosome breaks that appear to initiate DNA sequence amplification in hamster cells?

Genome instability is a hallmark of cancer cells. Biopsied tumor samples display highly rearranged karyotypes characterized by translocations, deletions, inversions, abnormally banding chromosome regions, and double minutes (Rowley 1989; Yunis 1981). Schimke et al. (1986) have proposed that this instability could engender several different modes of initiating DNA sequence amplification.

The findings of this report, however, suggest that all of these rearrangements are probably initiated by the same underlying mechanism-namely, chromosome breaks (with the possible exception of amplification mediated by double minutes). It is possible that one of the early, rate-limiting steps in the progression of a tumor is a mutation that affects the ability of the cell to repair singleor double-strand breaks. Breaks might naturally occur rather frequently as a consequence of occasional failures in the rejoining reaction carried out by either topoisomerase I or II during replication and/or transcription. Presumably, these breaks would almost always be repaired in a normal cell. The resulting unrepaired breaks that would befall the mutated cell could increase the frequency of gene amplification, accounting for the very high incidence of oncogene amplification in human tumors (Bishop 1987).

In this regard, it has been shown in recent years that the tumor suppressor gene, p53, is mutated in many human malignancies (Vogelstein 1990; Levine et al. 1991) and, more recently, that amplification of drug resistance markers can only be detected in cells that lack a wildtype copy of the p53 gene (Livingstone et al. 1992; Yin et al. 1992). Coupled with the suggestion that p53 may down-regulate DNA replication after damage delivered via ionizing radiation (Kastan et al.), it is possible that p53 is part of a damage-sensing signal transduction pathway that normally delays cell cycle progression until such potentially harmful damage can be repaired.

\section{Materials and methods}

Cells and cell culture

All cells were grown in minimal essential medium supplemented with nonessential amino acids, $12.5 \%$ fetal calf serum, penicillin, and gentamicin in $8 \% \mathrm{CO}_{2}$. Independent drug-resistant populations were selected from a single starting $\mathrm{CHO}-\mathrm{K} 1$ clone in three incremental steps $[0.02,0.1$, and $0.4 \mu \mathrm{M}$, as described previously (Trask and Hamlin 1989). At each drug level, 2-3 weeks were required to obtain $10^{7}$ cells. Resistant variants were maintained as populations at each level to avoid an addi- 
tional selection based on cloning efficiency. Populations E/0.4 and $C / 0.4$ were maintained for an additional 3 and 6 weeks, respectively, before mitotic cells were collected for analysis. In pilot studies employing a probe specific for the DHFR locus, we observed no amplification in any of the $\mathrm{CHO} / 0.02 \mu \mathrm{M}$ resistant populations. (Note that based on the starting cell number and the subsequent FISH patterns, it is likely that the variants in each of the nine original populations arose from an independent event or events; see Trask and Hamlin 1989).

For FISH analyses, metaphase cells were collected by shakeoff from $\sim 70 \%$ confluent monolayer cultures after a $1.5-\mathrm{hr}$ incubation in $0.1 \mu \mathrm{g} / \mathrm{ml}$ of colcemid. The harvested cells were incubated in $75 \mathrm{mM} \mathrm{KCl}$ at $37^{\circ} \mathrm{C}$ for $15 \mathrm{~min}$, fixed several times in fresh $3: 1$ methanol/acetic acid, and dropped onto cleaned slides. The slides were incubated at $65^{\circ} \mathrm{C}$ for $4 \mathrm{hr}$ and stored at $-20^{\circ} \mathrm{C}$ in sealed bags flushed with $\mathrm{N}_{2}$ until use.

\section{Construction and screening of the MACHO genomic library}

High-molecular-weight genomic DNA from $\mathrm{CHO}-\mathrm{Kl}$ cells was prepared as described previously ( $\mathrm{Ma}$ et al. 1990) and was digested partially with Sau3A1. The digest was separated on a $\mathrm{NaCl}$ gradient, the $30-50 \mathrm{~kb}$ fractions were pooled, and the fragments were cloned into the $B a m H I$ site of dephosphorylated PWE-16 (Wahl et al. 1987). The library contains more than $5 \times 10^{5}$ independent clones. Individual clones were tested in combination with the DHFR-specific cosmid cHl for their chromosomal position relative to the DHFR gene in in situ hybridization studies. Of a total of 106 clones screened from the MACHO library, 15 hybridized specifically to the $2 q$ arm; 5 of these clones were employed in this study.

\section{FISH}

FISH analyses were performed as described in detail elsewhere (Trask 1991; Trask et al. 1989), with some modifications. The DHFR-specific cosmid was labeled with digoxigenin-DUTP (Boehringer Mannheim), and the other cosmids were labeled with biotin-DUTP (Enzo Biochemicals or BRL), using a commercial nick-translation kit (BRL) supplemented with DNase I (BRL) to produce fragments $200-400 \mathrm{bp}$ in size. Selected pairs of labeled cosmids were mixed and hybridized to metaphase spreads. The hybridization volume was $10 \mu \mathrm{l}$ and contained 1 $\mathrm{ng} / \mu \mathrm{l}$ of each labeled cosmid, $1 \mu \mathrm{g} / \mu \mathrm{l}$ of sonicated total genomic CHO-KI DNA, $50 \%$ formamide, $2 \times$ SSC, and $10 \%$ dextran sulfate $(\mathrm{pH} 7.0)$. The hybridization solution was heated at $72^{\circ} \mathrm{C}$ for $5 \mathrm{~min}$ and was allowed to incubate at $37^{\circ} \mathrm{C}$ for $15 \mathrm{~min}$ before being applied to denatured slides/this step allows repetitive sequence elements in the probe to hybridize with their coun. terparts in the unlabeled blocking DNA). Hybridization took place at $37^{\circ} \mathrm{C}$ for $12-16 \mathrm{hr}$.

After washing, the slides were incubated sequentially in (1) avidin-Texas Red; (2) a combination of biotinylated goat-antiavidin and sheep anti-digoxigenin antibodies; and $\{3\}$ a combination of avidin-Texas Red and FITC-conjugated donkey antisheep IgG antibody as described elsewhere (Trask 1991; Trask et al. 1989). This treatment produced a red fluorescent signal at the sites of the biotinylated cosmid and a green fluorescent signal at the sites of the digoxigenin-labeled cosmid. All incubations were carried out at room temperature in PNM $10.1 \mathrm{M}$ phosphate buffer at $\mathrm{pH} 8.0,0.05 \% \mathrm{NP}-40,5 \%$ nonfat dry milk). The slides were washed between incubations in $2 \times$ SSC containing $0.005 \%$ CHAPS detergent (Pierce). The slides were rinsed in PN \{PNM minus milk\}, and $3 \mu$ l of anti-fade solution containing $0.02 \mu \mathrm{M}$ DAPI was applied to counterstain the chromosomes.

The slides were viewed and photographed on a Zeiss Axio- series microscope equipped with a $100 \times 1.3$ numerical aperture objective. Texas Red and FITC were simultaneously viewed through a double bandpass filter (Chromatechnology; excitation BP480-505/ BP560-595, reflector BP505-555/BP600-690, emission BP515-540/ BP610-660). DAPI fluorescence was viewed through a long-pass filter (Zeiss; BP360-371, FT395, LP397). Photographic images showing the three fluorochromes were obtained by double exposure through these two filter combinations /Scotch 3M 640T color slide film; $15 \mathrm{sec}$ exposures for Texas Red/FITC images, $\sim 1 \mathrm{sec}$ for DAPI). Figure 7, E and F, were obtained by photography through a single triple-band pass filter (Chromatechnology) for $15 \mathrm{sec}$.

\section{Hybridization data analysis}

Photographic slides of randomly selected metaphase spreads from each amplificant class were projected at $\sim 10^{4}$-fold magnification onto a digitizing board (Summagraphics). The digitizing board had 40 lines $/ \mathrm{mm}$ resolution. The coordinates of chromosome termini, centromeres, and probes were identified and entered via the digitizing board into a computer for further analysis. The distances between neighboring features along the amplified or marker chromosomes were calculated. Within each metaphase spread, the length of the unaffected $2 q$ arm was measured and used to normalize other measured distances. This normalization corrected for variations among metaphase spreads in the degree of chromatin condensation. For Figure 6, consensus chromosomes were calculated by averaging the normalized distances among centromere, DHFR, 2T probes, amplicon clusters, and termini for all chromosomes with common features within each amplificant class. A simple postscript program converted the normalized (and averaged) distance measurements into the diagrams shown in Figures 2, 4, 5, and 6.

The MACHO genomic library, bacterial clones, and animal cell lines are available for distribution.

\section{Acknowledgments}

We particularly express our appreciation to Dr. Ger van den Engh for his aid in developing the computer programs for chromosome analysis. We are also grateful to Carlton White, Kevin Cox, and Hillary Massa for expert and dedicated technical assistance. This work was supported by grants from the National Institutes of Health (NIH) to J.L.H. and from the NIH and the Department of Energy to B.J.T. S.M. was a fellow of the Howard Hughes Undergraduate Research Program at the University of Virginia. Methotrexate was a gift from the Drug Development Branch of the National Cancer Institute.

The publication costs of this article were defrayed in part by payment of page charges. This article must therefore be hereby marked "advertisement" in accordance with 18 USC section 1734 solely to indicate this fact.

\section{References}

Ardeshir, F., E. Giulotto, J. Zieg, O. Brison, W.S.L. Liav, and G.R. Stark. 1983. Structure of amplified DNA in different Syrian hamster cell lines resistant to $\mathrm{N}$-(phosphonacetyl)-Laspartate. Mol. Cell. Biol. 3: 2076-2088.

Barker, P.E. 1982. Double minutes in human tumor cells. Cancer Genet. Cytogenet. 5: 81-94.

Biedler, J.L. and B.A. Spengler. 1975. A novel chromosome abnormality in human neuroblastoma and antifolate-resistant Chinese hamster cells in culture. /. Natl. Cancer Inst. 57: 683-695. 
Bishop, J.M. 1987. The molecular genetics of cancer. Science 235: 305-311.

Brown, P.C., T.D. Tlsty, and R.T. Schimke. 1983. Enhancement of methotrexate resistance and dihydrofolate reductase gene amplification by treatment of mouse $3 \mathrm{~T} 6$ cells with hydroxyurea. Mol. Cell. Biol. 3: 1097-1107.

Deavan, L.L. and D.F. Peterson. 1973. The chromosomes of $\mathrm{CHO}$, an aneuploid Chinese hamster cell line: G-band, C-band, and autoradiographic analyses. Chromosoma 41: 129-144.

Debatisse, M., O. Hyrien, E. Petit-Koskas, R. de Saint Vincent, and G. Buttin. 1986. Segregation and rearrangement of coamplified genes in different lineages of mutant cells that overproduce adenylate deaminase. Mol. Cell. Biol. 6: 17761781.

Federspiel, N.A., S.M. Beverley, J.W. Schilling, and R.T. Schimke. 1984. Novel DNA rearrangements are associated with dihydrofolate reductase gene amplification. I. Biol. Chem. 259: 9127-9140.

Ford, M. and M. Fried. 1986. Large inverted duplications are associated with gene amplification. Cell 45: 425-430.

Galas, D.J. and M. Chandler. 1981. On the molecular mechanism of transposition. Proc. Nat1. Acad. Sci. 78: 4858-4862.

Guilotto, E., I. Saito, and G.R. Stark. 1986. Structure of DNA formed in the first step of CAD gene amplification. $E M B O J$. 5: 2115-2121

Hamlin, J.L., T.-H. Leu, J.P. Vaughn, C. Ma, and P.A. Dijkwel. 1991. Amplification of DNA sequences in mammalian cells. Prog. Nucleic Acid Res. 41: 203-239.

Harshey, R.M. and A.I. Bukhari. 1981. A mechanism of DNA transposition. Proc. Natl. Acad. Sci. 78: 1090-1094.

Horns, R.C., W.J. Dower, and R.T. Schimke. 1984. Gene amplification in a leukemic patient treated with methotrexate. $J$. Clin. Oncol. 2: 2-7.

Huberman, J.H. and A.D. Riggs. 1972. On the mechanism of DNA replication in mammalian chromosomes. J. Mol. Biol. 32: 327-341.

Hyrien, O. 1989. Large inverted duplications in amplified DNA of mammalian cells form hairpins in vitro upon DNA extraction but not in vivo. Nucleic Acids Res. 17: 9557-9569.

Kastan, M.B., O. Onyekwere, D. Sidransky, B. Vogelstein, and R.W. Craig. 1991. Participation of p53 protein in the cellular response to DNA damage. Cancer Res. 51: 6304-6311.

Kaufman, R.J. and R.T. Schimke. 1981. Amplification and loss of dihydrofolate reductase genes in a Chinese hamster ovary cell line. Mol. Cell. Biol. 1: 1069-1076.

Kaufman, R.J. and P.A. Sharp. 1982. Amplification and expression of sequences cotransfected with a modular dihydrofolate reductase complementary DNA gene. J. Mol. Biol. 159: 601-621.

Kaufman, R.J., P.C. Brown, and R.T. Schimke. 1979. Amplified dihydrofolate reductase genes in unstably methotrexate-resistant cells are associated with double minute chromosomes. Proc. Natl. Acad. Sci. 76: 5669-5673.

Levine, A.J., J. Momand, and C.A. Finlay. 1991. The p53 tumor suppressor gene. Nature 351: 453-456.

Livingstone, L.R., A. White, J. Sprouse, E. Livanos, T. Jacks, and T.D. Tlsty. 1992. Altered cell cycle arrest and gene amplification potential accompany loss of wild-type p53. Cell 70: $1-20$.

Looney, J.E. and J.L. Hamlin. 1987. Isolation of the amplified dihydrofolate reductase domain from methotrexate-resistant Chinese hamster ovary cells. Mol. Cell. Biol. 7: 569-577.

Looney, J.E., C. Ma, T.-H. Leu, W.F. Flintoff, W.B. Troutman, and J.L. Hamlin. 1988. The DHFR amplicons in different MTX-resistant Chinese hamster cell lines share at least a 273-kilobase core sequence, but the amplicons in some cell lines are much larger and are remarkably uniform in structure. Mol. Cell. Biol. 8: 5268-5279.

Ma, C., J.E. Looney, T.-H. Leu, and J.L. Hamlin. 1988. Organization and genesis of dihydrofolate reductase amplicons in the genome of a methotrexate-resistant Chinese hamster ovary cell line. Mol. Cell. Biol. 8: 2316-2327.

Ma, C., T.-H. Leu, and J.L. Hamlin. 1990. Multiple origins of replication in the dihydrofolate reductase amplicons of a methotrexate-resistant Chinese hamster cell line. Mol. Cell. Biol. 10: 1338-1346.

McClintock, B. 1941. The stability of broken ends of chromosomes in Zea mays. Genetics 26: 234-282.

Otto, E., S. McCord, and T.D. Tlsty. 1989. Increased incidence of $\mathrm{CAD}$ gene amplification in tumorigenic rat lines as an indicator of genomic instability of neoplastic cells. $J$. Biol. Chem. 264: 3390-3396.

Pinkel, D., T. Straume, and J.W. Gray. 1986. Cytogenetic analysis using quantitative, high-sensitivity, fluorescence hybridization. Proc. Natl. Acad. Sci. 83: 2934-2938.

Prody, C.A., P. Dreyfus, R. Zamir, H. Zakut, and H. Soreq. 1989. De novo amplification within a silent human cholinesterase gene in a family subjected to prolonged exposure to organophosphorous insecticides. Proc. Natl. Acad. Sci. 86: 690-694.

Rowley, J.D. 1989. Principles of molecular cell biology of cancer: Chromosomal abnormalities. In Principles and practice of oncology, 3d ed. \{ed. V.T. DeVita, S. Hellman, and S.A. Rosenberg), pp. 81-94. J.B. Lippincott Company, Philadelphia, PA.

Sager, R., I. Gadi, L. Stephens, and C.T. Grabowy. 1985. Gene amplification: An example of accelerated evolution in tumorigenic cells. Proc. NatI. Acad. Sci. 82: 7015-7019.

Schimke, R.T. 1982. Summary. In Gene amplification (ed. R.T. Schimkeł, pp. 317-333. Cold Spring Harbor Laboratory, Cold Spring Harbor, New York.

. 1988. Gene amplification in cultured cells. /. Biol. Chem. 263: 5989-5992.

Schimke, R.T., S.W. Sherwood, A.B Hill, and R.N. Johnston. 1986. Overreplication and recombination of DNA in higher eukaryotes: Potential consequences and biological implications. Proc. Natl. Acad. Sci. 83: 2157-2161.

Smith, K.A., P.A. Gorman, M.B. Stark, R.P. Groves, and G.R. Stark. 1990. Distinctive chromosomal structures are formed very early in the amplification of CAD genes in Syrian hamster cells. Cell 63: 1219-1227.

Smith, K.A., M.B. Stark, P.A. Gorman, and G.R. Stark. 1992. Fusions near telomeres occur very early in the amplification of CAD genes in Syrian hamster cells. Proc. Natl. Acad. Sci. 89: $5427-5431$.

Stark, G.R. and G.M. Wahl. 1984. Gene amplification. Annu. Rev. Biochem. 53: 447-491.

Stark, G.R., M. Debatisse, E. Giulotto, and G.M. Wahl. 1989. Recent progress in understanding mechanisms of mammalian DNA amplification. Cell 57: 901.

Tlsty, T.D. 1990. Normal diploid human and rodent cells lack a detectable frequency of gene amplification. Proc. Natl. Acad. Sci. 87: 3132-3136.

Tlsty, T.D., B. Margolin, and K. Lum. 1989. Differences in the rates of gene amplification in nontumorigenic and tumorigenic cell lines as measured by Luria-Delbruck fluctuation analysis. Proc. Natl. Acad. Sci. 86: 9441-9445.

Toledo, F., D. Le Roscouet, G. Buttin, and M. Debatisse. 1992. Co-amplified markers alternate in megabase long chromosomal inverted repeats and cluster independently in interphase nuclei at early stages of mammalian gene amplifica- 
tion. $E M B O J$. 11: 2665-2673.

Trask, B.J. 1990. Fluorescence in situ hybridization: Applications in cytogenetics and gene mapping. Trends Genet. 7: 149-154.

Trask, B.J. and J.L. Hamlin. 1989. Early dihydrofolate reductase gene amplification events in CHO cells usually occur on the same chromosome arm as the original locus. Genes \& Dev. 3: 1913-1925.

Trask, B.J., D. Pinkel, and G. van den Engh. 1989. The proximity of DNA sequences in interphase cell nuclei is correlated to genomic distance and permits ordering of cosmids spanning 250 kilobase pairs. Genomics 5: 710-717.

Trent, J.M., R.N. Buick, S. Olson, R.C. Horns, and R.T. Schimke. 1984. Cytologic evidence for gene amplification in methotrexate-resistant cells obtained from a patient with ovarian adenocarcinoma. J. Clin. Oncol, 2: 8-15.

Vogelstein, B. 1990. A deadly inheritance. Nature 348: 681-682.

Wahl, G.M. 1989. The importance of circular DNA in mammalian gene amplification. Cancer Res. 49: 1333-1340.

Wahl, G.M., K.A. Lewis, J.C. Ruiz, B. Rothenberg, J. Zhao, and G.A. Evans. 1987. Cosmid vectors for rapid genomic walking, restriction mapping, and gene transfer. Proc. Natl. Acad. Sci. 84: 2160-2164.

Windle, B.E., B.W. Draper, Y. Yin, S. O'Gorman, and G.M. Wahl. 1991. A central role for chromosome breakage in gene amplification, deletion formation, and amplicon integration. Genes \& Dev. 5: 160-174.

Wright, J.A., H.S. Smith, F.M. Watt, M.C. Hancock, D.L. Hudson, and G.R. Stark. 1990. DNA amplification is rare in normal human cells. Proc. Nat1. Acad. Sci. 87: 1791-1795.

Yin, Y., M.A. Tainsky, F.Z. Bischoff, L.C. Strong, and G.M. Wahl. 1992. Wild-type p53 restores cell cycle control and inhibits gene amplification in cells with mutant p53 alleles. Cell 70: 937-948.

Yunis, J.L. 1981. Specific fine chromosomal defects in cancer: An overview. Hum. Pathol. 12: 503-515.

Zieg, J., C.E. Clayton, F. Ardeshir, E. Giulotto, E.A. Swyryd, and G.R. Stark. 1983. Properties of single-step mutants of Syrian hamster cell lines resistant to $\mathrm{N}$-|phosphonacetyl|-L-aspartate. Mol. Cell. Biol. 3: 2089-2098. 


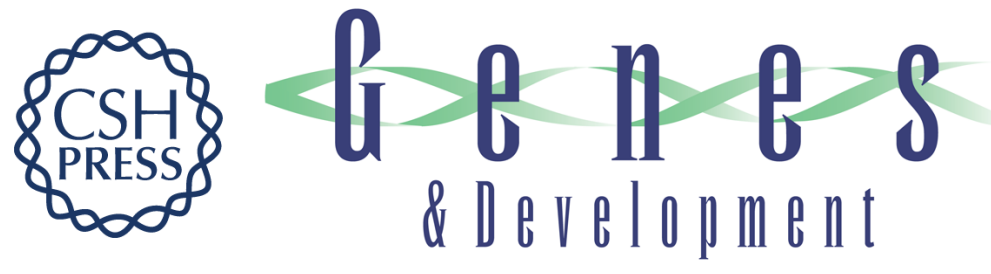

\section{Sister chromatid fusion initiates amplification of the dihydrofolate reductase gene in Chinese hamster cells.}

C Ma, S Martin, B Trask, et al.

Genes Dev. 1993, 7:

Access the most recent version at doi:10.1101/gad.7.4.605

References This article cites 52 articles, 32 of which can be accessed free at:

http://genesdev.cshlp.org/content/7/4/605.full.html\#ref-list-1

License

Email Alerting

Service

Receive free email alerts when new articles cite this article - sign up in the box at the top right corner of the article or click here.

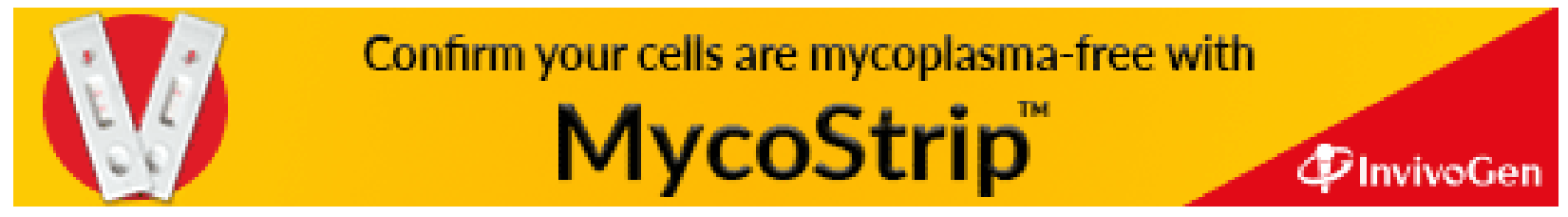

